\title{
Actein induces apoptosis in leukemia cells through suppressing RhoA/ROCK1 signaling pathway
}

\author{
WEN-DI ZHOU, XIANG WANG，XING-ZHEN SUN，JIAN HU，RONG-RONG ZHANG and ZE HONG
}

\begin{abstract}
Department of Pediatrics, Huai'an First People's Hospital, Nanjing Medical University, Huai'an, Jiangsu 223300, P.R. China
\end{abstract}
Received April 24, 2017; Accepted June 23, 2017

DOI: $10.3892 /$ ijo. 2017.4150

\begin{abstract}
Actein is a tetracyclic triterpenoid compound, extracted from the rhizome of Cimicifuga foetida, exhibiting anticancer activities as previously reported. However, the effects of actein on human leukemia have not been explored before. In this study, the role of actein in regulating apoptosis induction in human leukemia cells was investigated. Actein administration significantly enhanced apoptosis, especially in human leukemia cell line of U937 and the primary human leukemia cells. The promotion was accompanied by caspase-9, caspase-3 and poly(ADP-ribose) polymerase (PARP) cleavage, and cytochrome $c($ Cyto- $c$ ) release. Additionally, translocation of Bax into mitochondria was increased by actein, while antiapoptotic signals of myeloid cell leukemia-1 (Mcl-1) and B cell CLL/lymphoma 2 (Bcl-2) were decreased, accompanied by reduced phosphorylated Bcl-2-associated death promoter (Bad). Furthermore, protein kinase B (AKT) activation was downregulated by actein treatment in U937 cells. RhoA, but not caspase-3, regulated Rho kinase 1 (ROCK1) expression induced by actein. Suppression of RhoA and ROCK1 reduced ROCK1 expression, caspase-9, caspase-3 and PARP cleavage. In contrast, AKT inactivity enhanced apoptosis levels, as well as caspase signaling pathway expression. The anticancer role of actein was potentiated by inactivating AKT. In vivo, U937bearing tumor growth was suppressed by actein, which was related to ROCK1 suppression, AKT dephosphorylation and apoptosis induction. These results indicated that actein has a
\end{abstract}

Correspondence to: Dr Ze Hong, Department of Pediatrics, Huai'an First People's Hospital, Nanjing Medical University, 6 Beijing Road West, Huai'an, Jiangsu 223300, P.R. China

E-mail: hongze000000@foxmail.com; suokedixxmu@foxmail.com

Abbreviations: PARP, poly(ADP-ribose) polymerase; Cyto-c, cytochrome $c$; Mcl-1, myeloid cell leukemia-1; Bcl-2, B cell CLL/ lymphoma 2; Bad, Bcl-2-associated death promoter; AKT, protein kinase B; ROCK1, Rho kinase 1; PTEN, phosphatase and tensin homolog; FBS, fetal bovine serum; TUNEL, terminal deoxynucleotidyl transferase (TdT) dUTP nick-end labeling; MTT, 3-(4,5-dimethyl-2-thiazolyl)-2,5-diphenyl-2-H-tetrazolium bromide; Bax, Bcl-2-associated X protein; BCA, bicinchoninic acid

Key words: actein, human leukemia, apoptosis, RhoA, Rho kinase 1 suppressive role in human leukemia progression through inactivating RhoA/ROCK1 and inducing caspases.

\section{Introduction}

Presently, acute promyelocytic leukemia is characterized by the differentiation arrest during the promyelocytic stage and elevation of the hematopoietic stem cells $(1,2)$. Chemotherapy is the initial treatment of choice. Due to the abnormal collection of immature precursors, as well as the suppression of normal hemopoiesis, acute promyelocytic leukemia represents as a medical emergency, which causes a high level of early fatalities from the massive hemorrhage (3-5). Most patients with acute promyelocytic leukemia will receive a combination of medications. There are no surgical options owing to the body-wide distribution of malignant cells $(6,7)$. Therefore, finding effective and new therapeutic strategies and revealing the underlying molecular mechanisms regulating leukemia cells are necessary and could be beneficial and useful for patients with acute promyelocytic leukemia.

Actein is a tetracyclic triterpenoid compound, isolated from the rhizome of Cimicifuga foetida (8). Cimicifuga species has a long history for medicine to protect people suffering from rheumatism, sore throat, and diarrhea in North America (9). In Asia, Cimicifuga species are used owing to its various bioactivities, such as antidiabetic, anti-osteoporosis and antiviral (10). In addition, the extracts from rhizome of Cimicifuga species have been applied to prevent female-related diseases clinically (11). Hence, Cimicifuga species could be considered as a natural medicinal herb with promising medicinal values. Moreover, actein was selective for human breast tumor cells, which could synergize with other chemotherapy agents to inhibit tumor growth (12). Moreover, p53 signaling pathway was revealed to be modulated by actein (11). P53, as a tumor suppressor, plays an essential role in apoptosis induction through regulating caspases (13-15). However, the effects of actein on modulating tumor growth, including human leukemia, is poorly understood. Herein, we attempted to explore if actein could suppress human leukemia development though inducing apoptosis and to reveal the underlying molecular mechanism.

Rho-associated kinase (ROCK) is reported as a serine/ threonine kinase and one of the major downstream effectors of the small GTPase RhoA (16). The RhoA/ROCK signaling pathway is closely associated with the pathogenesis of various 
disorders and is also involved in a number of aspects of tumors, including human leukemia $(17,18)$. Rho could modulate the cell actin cytoskeleton through its down-stream effective factor of ROCK, which is highly included in the biological processes of cell movement, cell migration, gene transcription, nerve regeneration, and apoptosis $(19,20)$. Also, elevation of RhoA/ ROCK has been reported in tumors and associated with cancer development (21). Therefore, targeting RhoA/ROCK signaling pathway might be a potential therapeutic strategy for human leukemia treatment. Though it has been reported in leukemia progression, further study is still required to further reveal the underlying molecular mechanism. In this study, we attempted to explore the role of actein in modulating human leukemia cell progression through apoptosis induction, which relied on regulation of RhoA/ROCK1. In vivo, the U937-bearing tumor growth was inhibited by actein treatment. The suppressive role of actein in human leukemia included its effects on AKT dephosphorylation, phosphatase and tensin homolog (PTEN) activation, pro-apoptotic signal promotion as well as antiapoptotic molecule reduction. The results suggested that actein could be an effective candidate for human leukemia.

\section{Materials and methods}

Cells and culture. Human leukemia cell lines, U937, K562 and NB4, were purchased from American Type Culture Collection (ATCC, USA). Human hepatocyte cell line L02 and human tubular epithelial cells HK2 were purchased from KeyGen Biotech Co., Ltd. (Nanjing, China). All cells were cultured in RPMI-1640 medium, which is supplemented with $10 \%$ fetal bovine serum (FBS) (Gibco, Invitrogen, USA), $100 \mathrm{U} / \mathrm{ml}$ penicillin and $100 \mu \mathrm{g} / \mathrm{ml}$ streptomycin at $37^{\circ} \mathrm{C}$ in a $5 \% \mathrm{CO}_{2}$ humidified environment. The peripheral blood samples in our studies were isolated from 10 patients with acute promyelocytic leukemia after acquiring the informed consent: two patients are M2, four are M4, and four are M5 following the French-American-British (FAB) classification system. Approval for the study was obtained from Huai'an First People's Hospital, Nanjing Medical University (Jiangsu, China). Acute promyelocytic leukemia blasts were extracted using Histopaque-1077 density gradient centrifugation (Sigma-Aldrich, USA) for $15 \mathrm{~min}$ at $600 \mathrm{~g}$. The isolated mononuclear cells were then suspended in RPMI-1640 medium at $8 \times 10^{5} / \mathrm{ml}$. Peripheral blood mononuclear cells from blood samples collected from the healthy volunteers were also isolated by Histopaque 1077 density gradient centrifugation.

As for the gene knockdown, the cells were transfected with (100 nM) nonsense control, siRNA against caspase-3 (\#1:5'-UGU AGG AGA GUU GAG GUC GAG GU) and siRNA against ROCK1 (\#1:5'-GAU UAU AGA GUG GUG GUG ACG GGU A) for $24 \mathrm{~h}$ using Lipofectamine 2000 (Invitrogen) according to the manufacturer's protocol. All small interfering RNAs were synthesised by GenePharma (Shanghai, China). After various treatments, further experiments were conducted. Actein (CAS:18642-44-9, 98\% HPLC) used in our study was purchased from Shanghai Yuanye Bio-Technology Co., Ltd. (Shanghai, China). AKT inhibitor, LY294002, and caspase-3 inhibitor, Z-VAD-FMK, were purchased from Sigma-Aldrich, and ROCK1 inhibitor, Y-27632 dihydrochloride was obtained from Tocris Bioscience (Bristol, UK). RhoA inhibitor, C3 exoenzyme, was purchased from Alexis Biochemicals (USA).

Flow cytometric analysis. After treatment under various conditions, flow cytometric analysis was used to determine apoptosis levels in U937 cells using Annexin V/PI staining kit (Roche, Switzerland) following the manufacturer's protocol. In order to analyze the mitochondria injury, $2 \times 10^{5}$ U937 cells were cultured with 3,3-dihexyloxacarbocynine at the dose of $40 \mathrm{nM}$ ( $\mathrm{DiOC}_{6}$, Sigma-Aldrich) in PBS for $20 \mathrm{~min}$ at $37^{\circ} \mathrm{C}$. The results acquisition and analysis were performed using a Becton-Dickinson FACSCalibur flow cytometer with Cell Quest software.

Mitochondrial and cytosolic fractions. Mitochondria/cytosol fractionation kits (ab65320, Abcam, USA) were used to isolate the mitochondrial fraction from cytosolic fraction. Then, the enriched mitochondrial and cytosolic fractions were used for western blot analysis.

Hoechst 33258 staining. Hoechst 33258 staining of the cells was performed to evaluate the apoptosis induced by actein. The cells were seeded at a concentration of $1 \times 10^{6}$ cells $/ \mathrm{ml}$ in 6-well plates and treated with the indicated concentration of actein. The cells were harvested, washed twice with PBS, fixed with $4 \%$ formaldehyde for $10 \mathrm{~min}$ and stained with Hoechst 33258 (Sigma-Aldrich) staining solution following the manufacturer's instructions. The images were immediately photographed under a fluorescence microscope (Olympus, Japan).

Evaluation of apoptosis. After induction of actein for $24 \mathrm{~h}$, leukemia cell apoptosis was measured using a commercial single-stranded DNA (ssDNA) enzyme-linked immunosorbent assay kit (Millipore Chemicon, USA), which detects ssDNA, corresponding to the most specific apoptosis end-product.

\section{3-(4,5-dimethyl-2-thiazolyl)-2,5-diphenyl-2-H-tetrazolium} bromide (MTT) analysis. MTT (Beyotime, Nanjing, China) was used to calculate cell viability. Cells $\left(2 \times 10^{3} /\right.$ well $)$ were seeded on 96-well plates and treated under different conditions as indicated and incubated at $37^{\circ} \mathrm{C}$. MTT solution (300 $\mu \mathrm{l} /$ well) was added after incubation. Following incubation at $37^{\circ} \mathrm{C}$ for an additional $4 \mathrm{~h}$, the supernatants were removed and $200 \mu \mathrm{l}$ dimethyl sulfoxide (DMSO, Sigma-Aldrich) was added into each well to dissolve the formazan crystals. The 96-well plates were then placed in a microplate reader to determine the absorbance at $490 \mathrm{~nm}$. Each test was carried out in triplicate.

Animal treatments. Twenty, 5-week-old male nu/nu mice (15-18 g) were injected with $5 \times 10^{6}$ U937 cells subcutaneously. All mice were purchased from the Animal Experiment Center of Nanjing Medical University (Nanjing, China). Before the experiments, all mice were allowed to adapt to the environment for a week. All protocols were in line with the Regulations of Experimental Animal Administration issued by the Ministry of Science and Technology of the People's Republic of China. Mouse care and usage were performed according to the ethical guidelines of Huai'an First People's Hospital, Nanjing Medical University. The mice were raised in air-conditioned 
pathogen-free rooms $\left(25 \pm 2^{\circ} \mathrm{C}, 50 \pm 10 \%\right.$ humidity) under controlled lighting (12 h light/day) and fed with water and standard laboratory food. When the tumors were visible, the mice were randomly divided into two groups (10 mice per group). The control group received the vehicle (PBS) injection i.p., and the treatment group was administered with actein i.p. every day at a dose of $15 \mathrm{mg} / \mathrm{kg}$ (11). Sixty days later, all mice were sacrificed, tumors were excised and measured, and tumor tissues were fixed in $10 \%$ formalin. After embedding in paraffin, immunohistochemical analysis was performed.

Immunofluorescent analysis. U937 cells were treated with or without $40 \mu \mathrm{M}$ actein for $24 \mathrm{~h}$. Cells were then harvested through centrifugation, and fixed with $4 \%$ paraformaldehyde for $10 \mathrm{~min}$, permeabilized using $0.1 \%$ Triton X-100 for $10 \mathrm{~min}$, and finally blocked with $1 \%$ bovine serum albumin for $30 \mathrm{~min}$ at room temperature. Cells were further incubated with a primary antibody (Cyto- $c$, 1:200, Abcam) at $4^{\circ} \mathrm{C}$ overnight, and followed by a secondary goat anti-mouse IgG H\&L (Alexa Fluor ${ }^{\circledR} 488$ ) (Abcam) for $1 \mathrm{~h}$ at room temperature. After washing with PBS, the images were captured with a confocal microscope (Olympus, Japan).

Immunohistochemical assays. Paraffin-embedded tumor sections were used for the blinded assessment of caspase-3, Ki-67, ROCK1 and apoptosis levels, respectively. Mouse tumors were sectioned at $3 \mu \mathrm{M}$ thickness, and terminal deoxynucleotidyl transferase (TdT) dUTP nick-end labeling (TUNEL) assay was carried out using light and electron microscopy-based kits (R\&D Systems, USA) for detecting DNA fragments. For staining of ROCK1 (1:200, Abcam, UK), caspase-3 (1:200,Abcam) and Ki-67 (1:200,Abcam), the tumor sections were analyzed using a microscope. Images were arranged using the TissueFAXs (Tissue-Gnostics) software.

Western blot analysis. For western blotting, cells and tissue samples after various treatments were lysed in RIPA lysis buffer $(150 \mathrm{mM} \mathrm{NaCl}, 0.1 \%$ Triton $\mathrm{X}-100,0.5 \%$ sodium deoxycholate, $0.1 \%$ SDS, and $50 \mathrm{mM}$ Tris- $\mathrm{HCl}, \mathrm{pH} 8.0$ ) to yield a homogenate. Also, the final supernatants were obtained by centrifugation at $12,000 \mathrm{~g}$ for $15 \mathrm{~min}$. The protein concentration was calculated using bicinchoninic acid (BCA) protein assay kit (Thermo Scientific, USA) with bovine serum albumin as a standard. The total protein extract was later used for western blot analysis. Total protein $(40 \mu \mathrm{g})$ was loaded and proteins were separated using SDS-PAGE and electrophoretically transferred to polyvinylidene difluoride membranes (Millipore, USA). The membranes were then blocked with 5\% non-fat dry milk in Tris buffered saline (20 mM Tris, $\mathrm{pH} 7.6,137 \mathrm{mM}$ $\mathrm{NaCl}$ ) with $0.1 \%$ Tween-20, washed, and then incubated with primary antibody. The primary antibodies were as follows: rabbit anti-p-AKT (1:1,000, Cell Signaling Technology), rabbit anti-AKT (1:1,000, Cell Signaling Technology), rabbit anti-Mcl-1 (1:1,000, Abcam), rabbit anti-Bcl-xl (Abcam, USA), rabbit anti-Bax (1:1,000, Abcam), rabbit anti-PTEN (1:1,000, Abcam), rabbit anti-p-PTEN (1:1,000, Abcam), rabbit anti-caspase-3 (1:1,000, Abcam), mouse anti-Bcl-2 (1:1,000, Cell Signaling Technology), rabbit anti-PARP (1:1,000, Cell Signaling Technology), rabbit anti-p-Bad (1:1,000, Abcam), rabbit anti-Bad (1:1,000, Abcam), rabbit anti-RhoA (1:1,000,
Abcam), rabbit anti-ROCK1 (1:1,000, Abcam), rabbit antiCox IV (1:1,000, Abcam), mouse anti-Cyto- $c$ (1:1,000, Abcam) and anti-GAPDH (1:500, Santa Cruz Biotechnology, Inc.). Immunoreactive bands were visualized by ECL Immunoblot Detection system (Pierce Biotechnology, Inc., Rockford, IL, USA) and exposed to Kodak (Eastman Kodak Co., USA) $\mathrm{X}$-ray film. Each protein expression level was defined as grey value (Version 1.4.2b, Mac OS X, ImageJ, National Institutes of Health, USA) and standardized to housekeeping gene of GAPDH and expressed as a fold of control.

Statistical analysis. Results are represented as the mean \pm SEM of triplicate experiments. Statistically significant values were compared by use of the ANOVA and the Dunnett's post hoc test, and P-values of $<0.05$ were considered to indicate a statistically significant result.

\section{Results}

Actein triggers apoptosis and mitochondrial damage in human leukemia cells. Actein has been investigated in human breast cancer though apoptosis induction $(10,11)$. Thus, here we first examined the role of actein in apoptosis and the mitochondrial injury in human leukemia cells, U937. Treating U937 cells with different concentrations of actein for $24 \mathrm{~h}$ significantly enhanced apoptosis (Fig. 1A, left) and mitochondrial injury in a dose-dependent manner (Fig. 1B, left). Furthermore, U937 cells were treated with $40 \mu \mathrm{M}$ actein for the indicated time, ranging from 0 to $24 \mathrm{~h}$. Flow cytometric analysis indicated that apoptosis was highly induced (Fig. 1A, right). Also, the mitochondria injury was observed in actein-treated cells, which was time-dependent (Fig. 1B, right). Following, the proteins isolated from total cell and cytoplasm, respectively, were used for western blot analysis. The results indicated that caspase-9, caspase-3 and PARP cleavage was dramatically increased after actein administration dose-dependently. Similarly, Cyto- $c$ was found to be upregulated with the increasing of actein treatment in cytoplasm, indicating actein administration promoted Cyto- $c$ release into the cytoplasm (Fig. 1C, left). In line with the results of flow cytometry, caspase-9, caspase-3 and PARP activation was significantly improved after actein treatment, which was shown in a time-dependent manner (Fig. 1C, right). Furthermore, Hoechst 33258 staining indicated that the number of apoptosis was significantly high in U937 and K562 cells after actein treatment (Fig. 2A). Cell apoptosis was also evaluated using ssDNA detection kit. Untreated leukemia cells served as the control. As shown in Fig. 2B, we found that treatment of actein significantly increased the apoptosis proportion in leukemia cell lines, and consistently, U937 cells were more sensitive to actein treatment. Also, western blot analysis indicated that caspase-9, caspase-3, and PARP cleavage and Cyto- $c$ in cytoplasm were apparently induced by actein in 937 and K562 cells (Fig. 2C). The results here indicated that U937 and K562 are likely to be more sensitive to actein. Taken together, the data above indicated that actein could potentiate apoptosis in human leukemia cells.

Actein induces apoptosis response in primary human leukemia cells. We attempted to evaluate if actein could induce apoptosis in human primary leukemia cells. The 

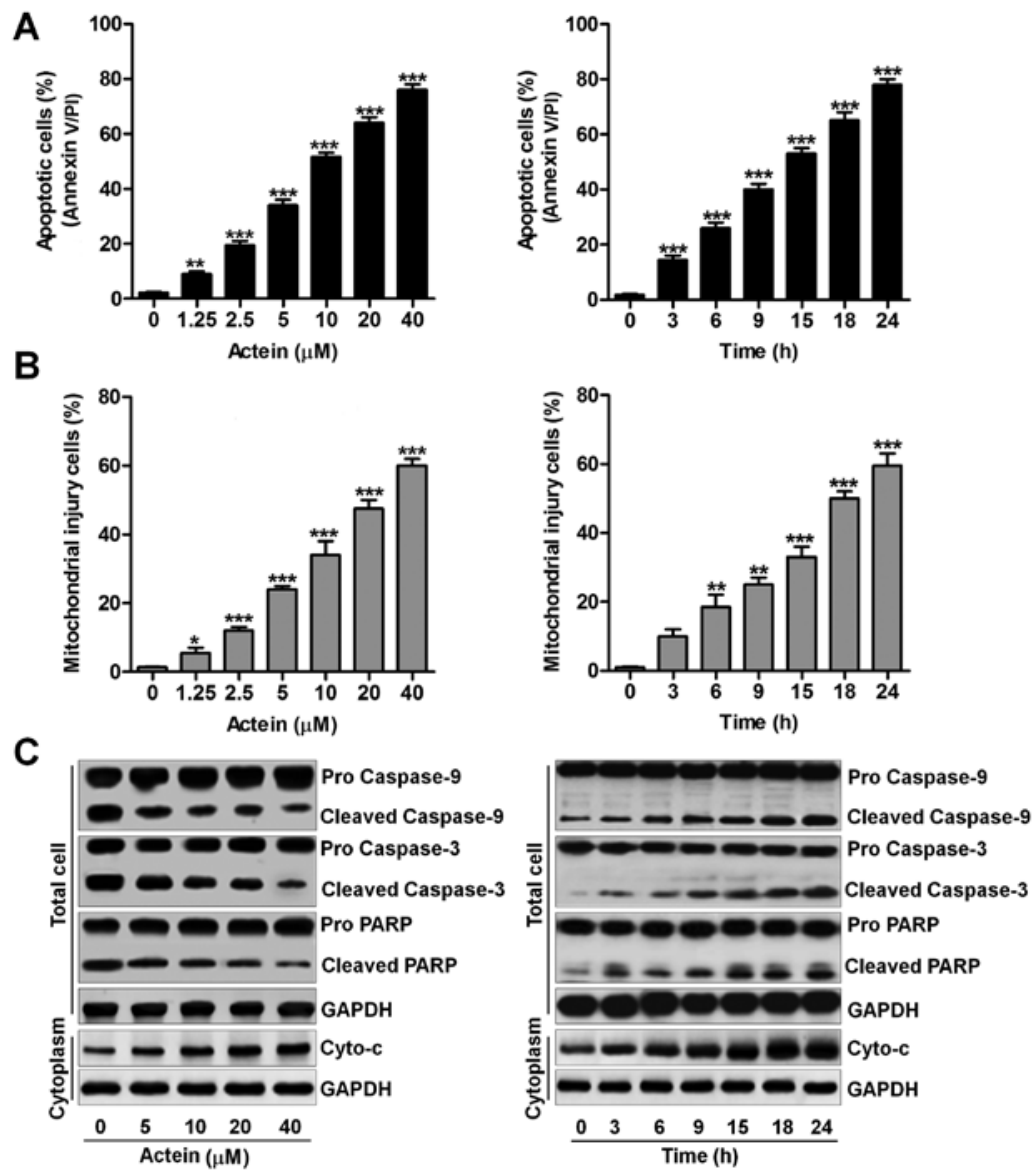

Figure 1. Actein triggers apoptosis and mitochondrial damage in human leukemia cells. (A) Left, the human leukemia cells of U937 were exposed to actein at the indicated concentrations, ranging from 0 to $40 \mu \mathrm{M}$ as indicated for $24 \mathrm{~h}$. After treatments, all cells were harvested for apoptotic analysis using flow cytometry. Right, U937 cells were cultured with $40 \mu \mathrm{M}$ actein for, respectively, $0,3,6,9,15,18$ or $24 \mathrm{~h}$. Then, all cells were collected for calculating the number of apoptotic cells using flow cytometry. (B) Left, U937 cells were treated at different doses of actein as described for $24 \mathrm{~h}$ and stained with DiOC 6 . Then, flow cytometric analysis was used to evaluate the number of cells experiencing mitochondrial injury. Right, U937 cells were treated with $40 \mu \mathrm{M}$ actein for the indicated time, followed by $\mathrm{DiOC}_{6}$ staining. Next, all cells were harvested for flow cytometric assays. (C) All U937 cells were treated as described. The extracts from the whole cells and the cytoplasm were used for western blot analysis using primary antibodies of caspase-9, caspase-3, PARP and Cyto- $c$. Data are analyzed as mean $\pm \mathrm{SEM}, \mathrm{n}=8 .{ }^{*} \mathrm{P}<0.05,{ }^{* *} \mathrm{P}<0.01$ and ${ }^{* * * *} \mathrm{P}<0.001$ versus the Con group in the absence of any treatments.
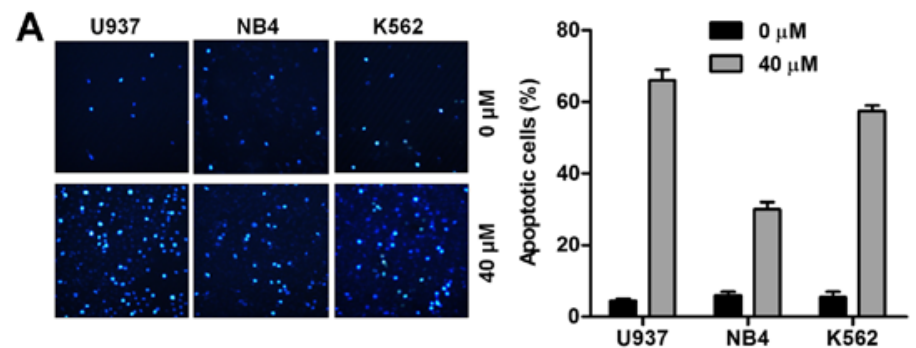

B

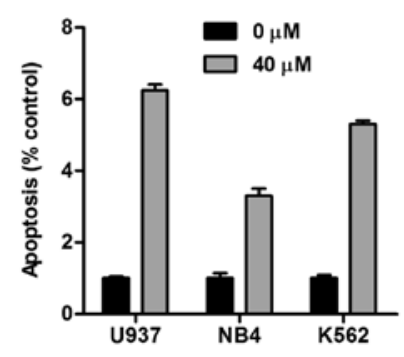

C

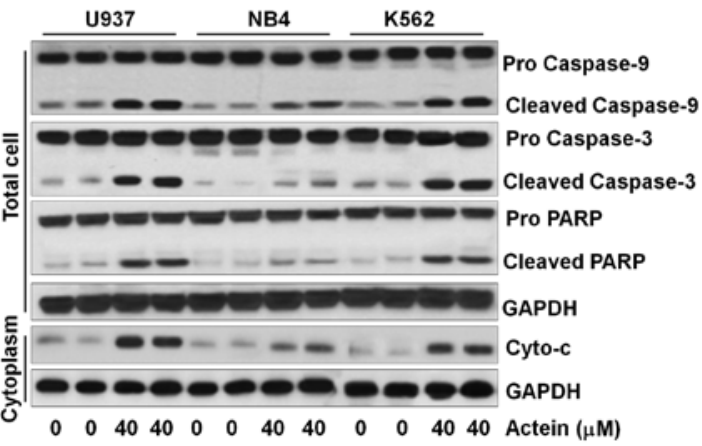

Figure 2. Actin induces apoptosis selectively in human leukemia cell lines. (A) Hoechst 33258 staining was used to calculate the effects of actein on different human leukemia cell lines treated with $40 \mu \mathrm{M}$ actein for $24 \mathrm{~h}$. (B) Cell apoptosis was evaluated using ssDNA detection kit. (C) Human leukemia cell lines, including U937, NB4 and K562, were exposed to $40 \mu \mathrm{M}$ actein for $24 \mathrm{~h}$, followed by western blot analysis of caspase-9, caspase-3, PARP and Cyto- $c$ in the whole cell or the cytoplasm as indicated. Data are analyzed as mean \pm SEM, $\mathrm{n}=8$. 
A

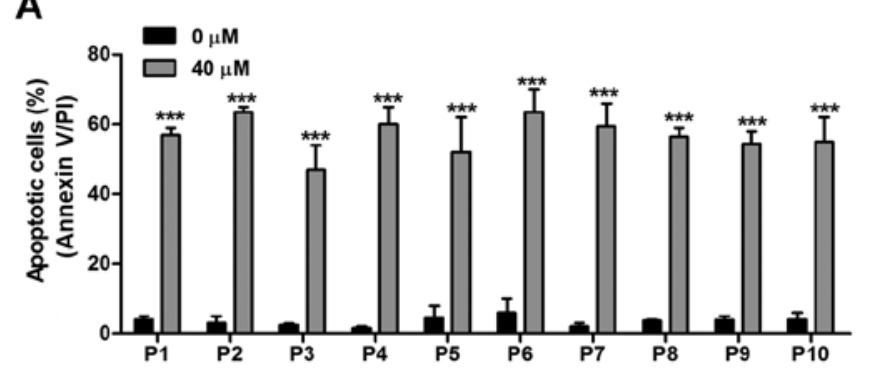

C

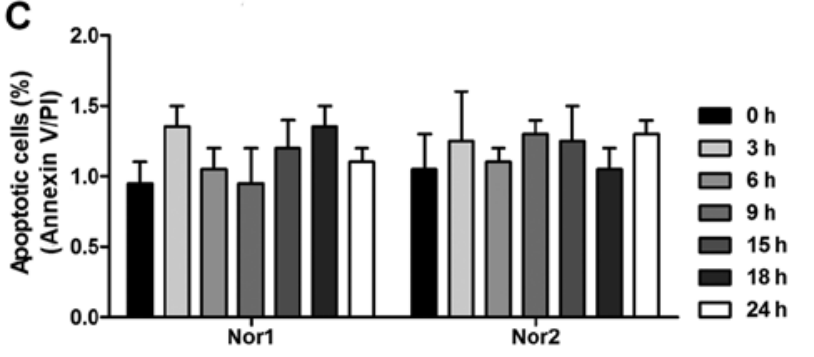

E
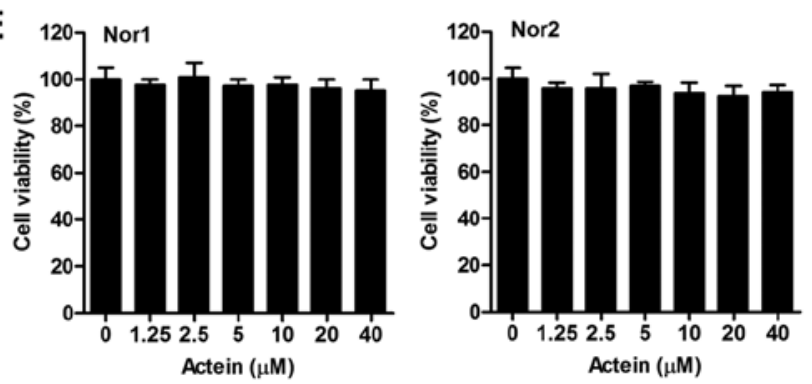

B

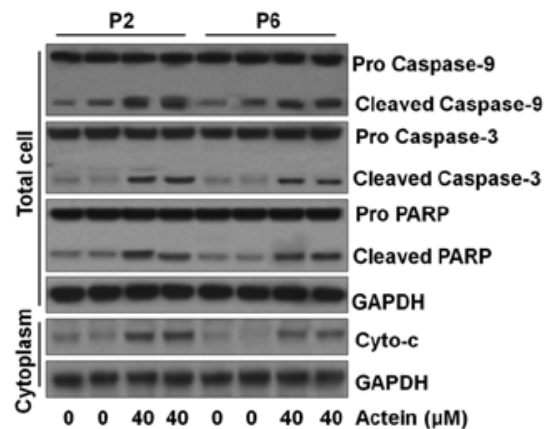

D
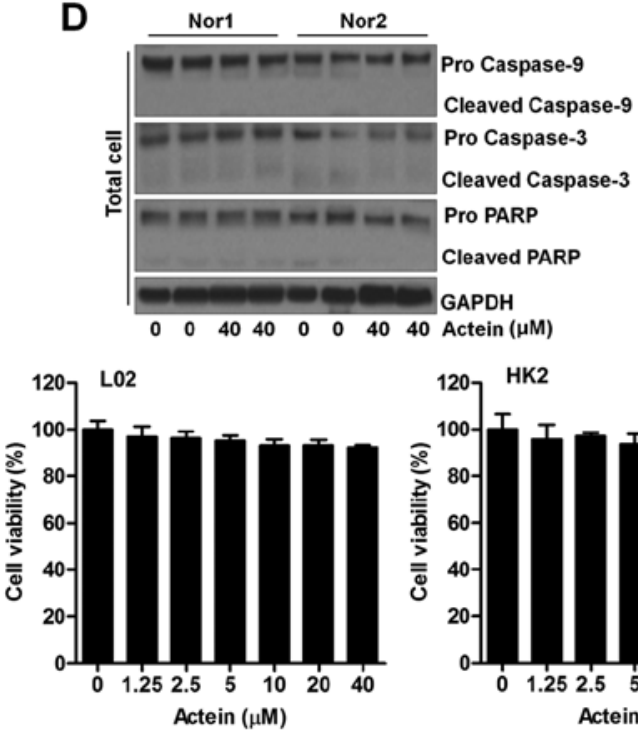

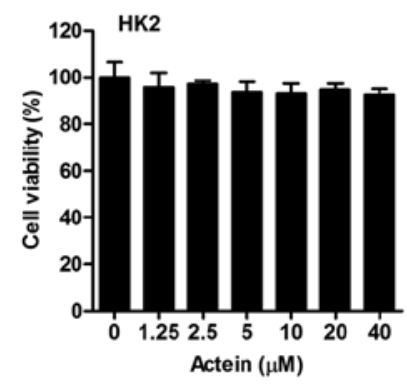

Figure 3. Actein induces apoptotic response in primary human leukemia cells. (A) Primary human leukemia cells were derived from peripheral blood of 10 patients. Immediate after treatment with actein $(40 \mu \mathrm{M})$ for $24 \mathrm{~h}$, the percentage of apoptotic cells was calculated through flow cytometry. (B) The lysates from the whole cell and the cytosolic fractions in leukemia cells extracted from two patients with acute myeloid leukemia were collected for western blot analysis of caspase-9, caspase-3, PARP and Cyto- $c$. (C) Peripheral blood mononuclear cells isolated from normal human were cultured with $40 \mu \mathrm{M}$ actein for $0,3,6,9,15,18$ and $24 \mathrm{~h}$. Then, flow cytometry was carried out to evaluate the number of apoptosis. (D) Peripheral blood mononuclear cells obtained from normal healthy people were exposed to $40 \mu \mathrm{M}$ actein for $24 \mathrm{~h}$, followed by assessment of caspase-9, caspase-3, PARP and Cyto- $c$ using western blot analysis. (E) Peripheral blood mononuclear cells, human hepatocyte cell line L02 and human tubular epithelial cells HK2 were exposed to actein for $24 \mathrm{~h}$ at the indicated concentrations. Then, all cells were harvested for MTT analysis. Data are analyzed as mean $\pm \mathrm{SEM}, \mathrm{n}=8$. ${ }^{* * *} \mathrm{P}<0.001$ versus the Con group in the absence of any treatment.

human primary leukemia cells were extracted from 10 patients with acute myeloid leukemia. Then, actein was administered to cells. As shown in Fig. 3A, we found that actein significantly induced apoptosis in human primary leukemia cells. Western blot analysis further indicated that the activation of caspase-9, caspase-3 and PARP was markedly induced in actein-treated primary leukemia cells obtained from two patients. Also, Cyto- $c$ releasing in the cytoplasm of human primary leukemia cells was also induced by using actein (Fig. 3B). Next, the effects of actein on peripheral blood mononuclear cells obtained from normal healthy people were explored. As shown in Fig. 3C, cells exposed to $40 \mu \mathrm{M}$ actein for various times showed no significant difference on apoptosis induction. In addition, western blot analysis in peripheral blood mononuclear cells and cytoplasm indicated that caspase-9, caspase-3, PARP and Cyto- $c$ were not alternative either in the group with actein exposure or not (Fig. 3D). Peripheral blood mononuclear cells, human hepatocyte cell line L02 and human tubular epithelial cells HK2 were exposed to actein for $24 \mathrm{~h}$ at the indicated concentartions. Then, all cells were harvested for MTT analysis. From the results in Fig. 3E, we found that there was no significant difference between the groups of cells. The results indicated that actein at the indicated concentrations used in our study showed no cytotoxicity to normal cells. The findings above indicated that actein could trigger apoptosis in human primary leukemia cells without any changes in peripheral blood mononuclear cells from normal people.

Actein causes apoptosis through regulating pro- and antiapoptotic signals. Anti-apoptotic and pro-apoptotic signals are well characterized in regulating apoptosis $(22,23)$. Thus, in order to explore the underlying molecular mechanism regarding to actein-induced apoptosis in human leukemia. Protein levels in total cellular, cytoplasm and mitochondria were calculated using western blot analysis. As shown in Fig. 4A, we found that Bcl-2, Bcl-xl and Mcl-1 expressed highly in actein-treated U937 cells. Bad phosphorylation, suppressing apoptosis, was reduced by actein. In contrast, Bad was observed with increased levels after actein administration in whole cells. Bax in cytoplasm was discovered with reduced protein abundance in actein-treated cells dose-dependently. Accordingly, in mitochondria, Bax was elevated, which indicated the ability 


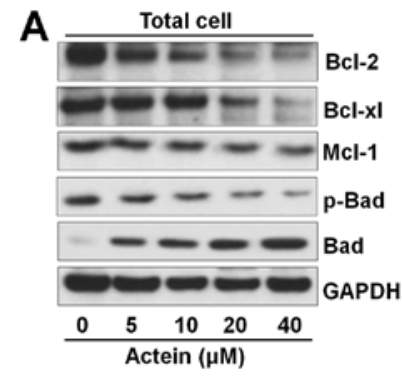

B

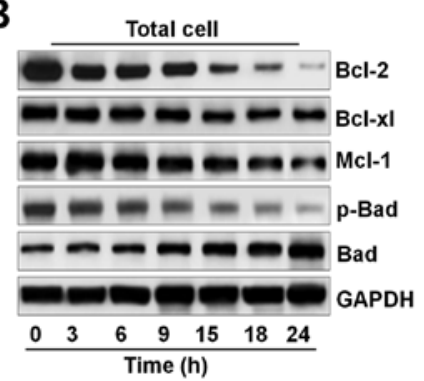

Cytoplasm
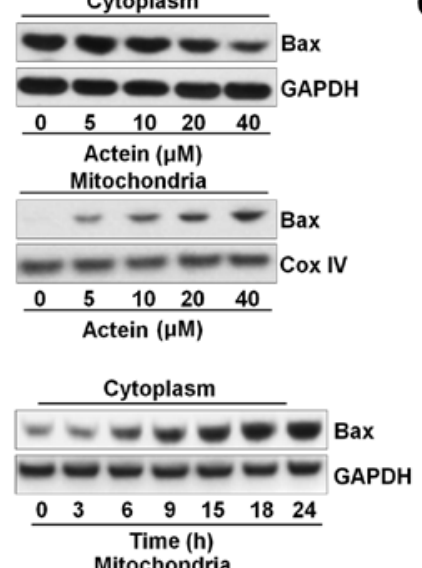

Mitochondria

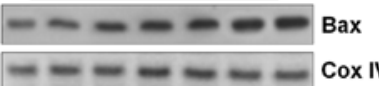

\begin{tabular}{lllllll}
0 & 3 & 6 & 9 & 15 & 18 & 24 \\
\hline \multicolumn{5}{c}{ Time (h) }
\end{tabular}

E

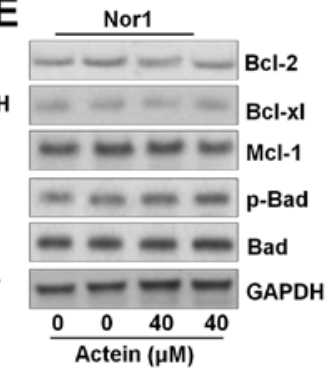

C
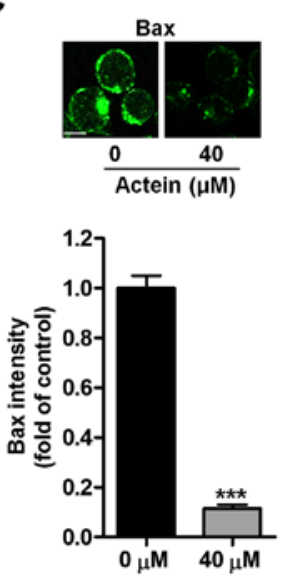

Nor1 : Cytoplasm

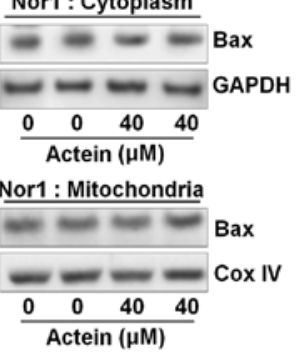

Figure 4. Actein causes apoptosis through regulating pro- and anti-apoptotic signals. (A) U937 cells were treated with actein ( $0,5,10,20$ and $40 \mu \mathrm{M})$ for $24 \mathrm{~h}$, followed by western blot analysis of Bcl-2, Bcl-xl, Mcl-1, p-Bad and Bad in the total cells. Also, protein extracted from cytoplasm and mitochondria was used for Bax using western blot assays. (B) U937 cells were treated with $40 \mu \mathrm{M}$ actein for the indicated time. Next, western blot analysis was used to assess the whole cellular Bcl-2, Bcl-xl, Mcl-1, p-Bad and Bad. Protein extracted from cytoplasm and mitochondria was used for Bax abundance from protein levels through western blot assays. (C) Actein $(40 \mu \mathrm{M})$ was exposed to U937 cells for $24 \mathrm{~h}$. After treatments, all cells were performed for immunofluorescent analysis. (D) Acute myeloid leukemia blasts and (E) peripheral blood mononuclear cells from normal people were exposed to $40 \mu \mathrm{M}$ actein for $24 \mathrm{~h}$, followed by western blot analysis of the whole cellular Bcl-2, Bcl-xl, Mcl-1, p-Bad and Bad, as well as Bax in cytoplasm and mitochondria. Data are analyzed as mean \pm SEM, $\mathrm{n}=8$. ${ }^{* * *} \mathrm{P}<0.001$ versus the Con group in the absence of any treatment.

of actein in inducing apoptosis. The results above were also triggered by actein in a time-dependent manner in U937 cells (Fig. 4B). Furthermore, immunofluorescent analysis confirmed that the expression of Bax, proved by the fluorescent intensity, in cytoplasm was suppressed by actein (Fig. 4C). Also, primary leukemia cells isolated from patient indicated that anti-apoptotic molecules of Bcl-2, Bcl-xl and Mcl-1 were suppressed by actein administration, as well as phosphorylated Bad, while Bad was significantly triggered. Additionally, actein reduced Bcl-2-associated X protein (Bax) expression in cytoplasm, and elevated its levels in mitochondria (Fig. 4D). Finally, western blot analysis of peripheral blood mononuclear cells extracted from normal people showed no difference of these signals in expression (Fig. 4E).

Actein treatment suppresses AKT and RhoA/ROCKI signaling pathway. Referring to previous studies, PTEN and PI3K/AKT signaling pathway is involved in regulating apoptosis (24). PTEN is reported to negatively modulate the activation of PI3K/AKT $(25,26)$. In this regard, we found that phosphorylated PTEN was highly induced by actein treatment in a dose- and time-dependent manner, subsequently reducing AKT phosphorylated levels (Fig. 5A and B). Similar
A

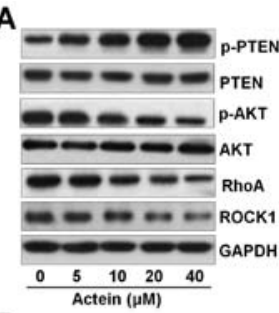

B
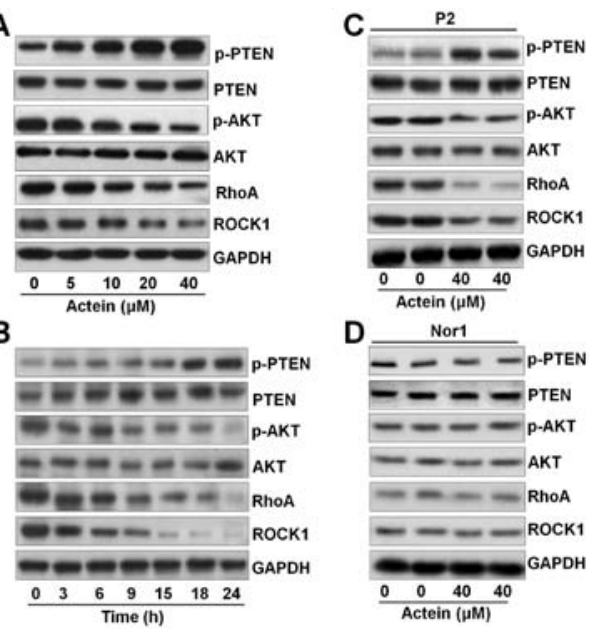

Figure 5. Actein treatment suppresses AKT and RhoA/ROCK1 signaling pathway. (A) U937 cells were exposed to actein at the described concentrations $(0-40 \mu \mathrm{M})$ for $24 \mathrm{~h}$ or (B) treated for the indicated time, ranging from 0 to $24 \mathrm{~h}$, with $40 \mu \mathrm{M}$ actein. Then, the cells were harvested for western blot analysis using primary antibodies of p-PTEN, PTEN, p-AKT, AKT, RhoA and ROCK1. (C) Acute myeloid leukemia blasts and (D) peripheral blood mononuclear cells from normal people were treated with $40 \mu \mathrm{M}$ actein for $24 \mathrm{~h}$. Next, western blot analysis was carried out to evaluate the protein levels of p-PTEN, PTEN, p-AKT, AKT, RhoA and ROCK1. Data are analyzed as mean \pm SEM, $n=8$. 

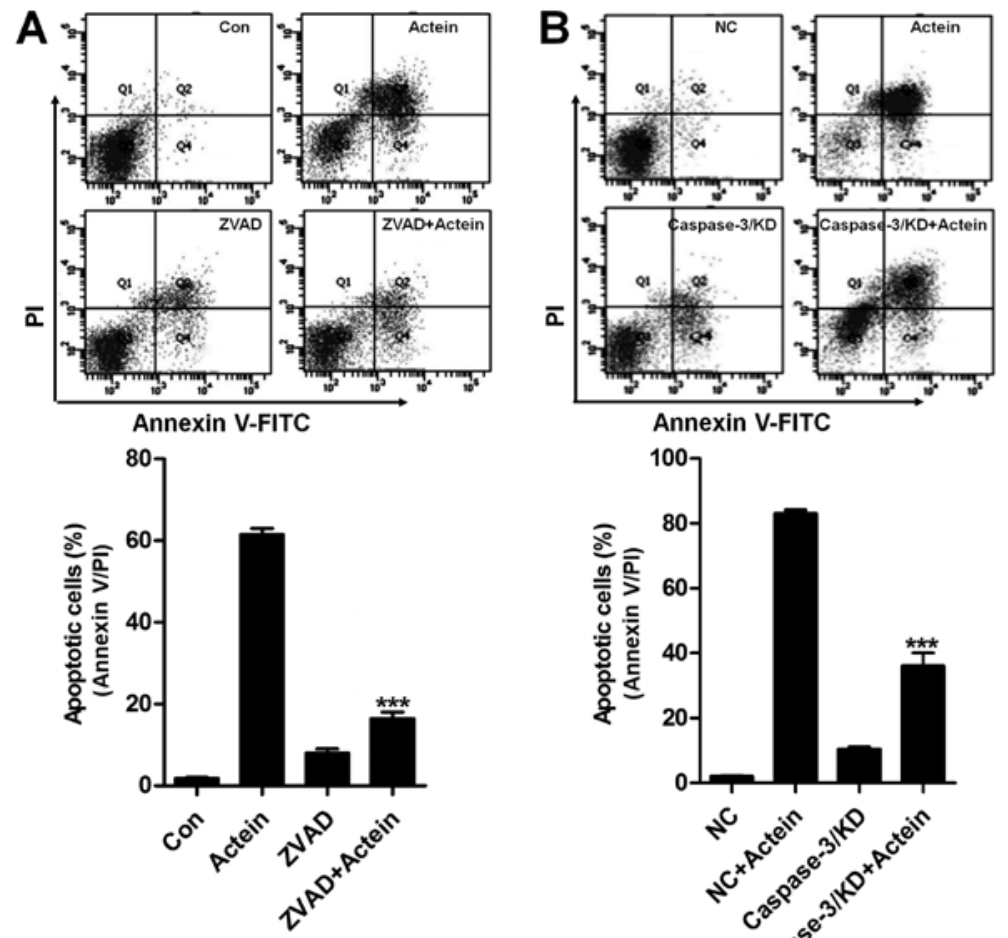

C
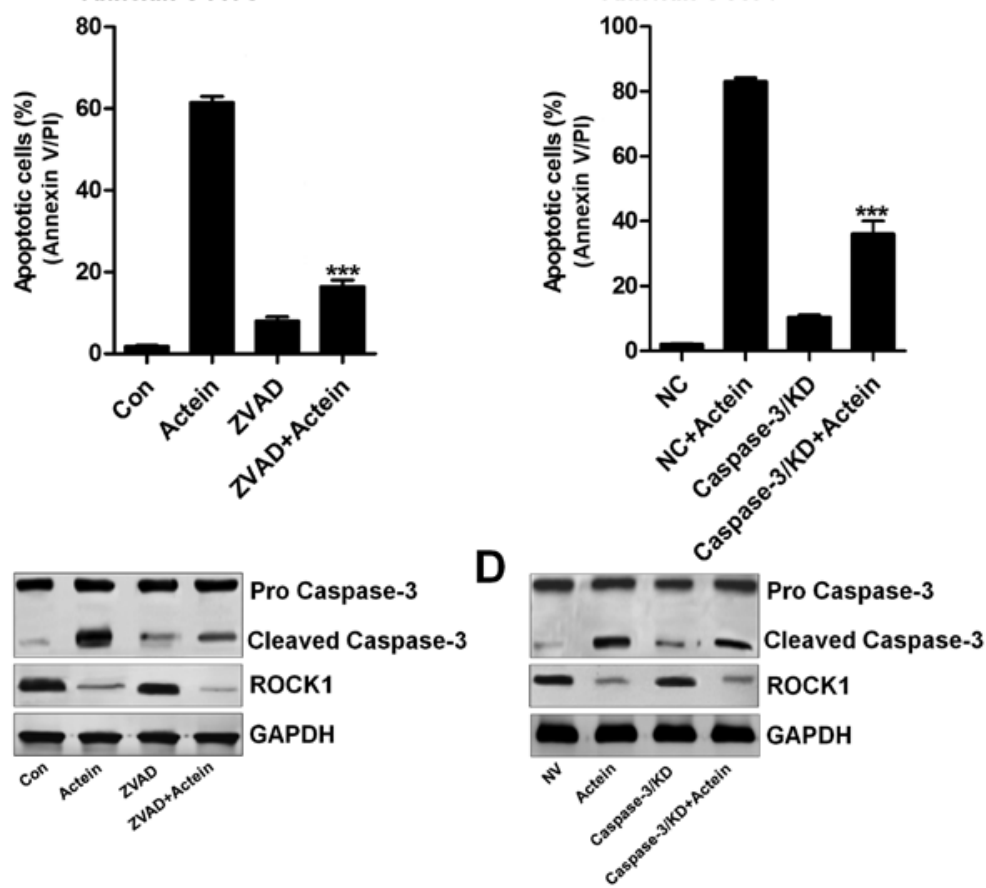

Figure 6. Caspase-3-independent ROCK1 activation is involved in actein-induced apoptosis. (A) U937 cells were pre-treated with $20 \mu \mathrm{M}$ caspase-3 inhibitor, ZVAD, for $2 \mathrm{~h}$ and then exposed to $40 \mu \mathrm{M}$ actein for $24 \mathrm{~h}$, followed by flow cytometric analysis. (B) U937 cells were transfected with caspase-3 siRNA for $24 \mathrm{~h}$ to knockdown caspase-3 expression, followed by exposure to $40 \mu \mathrm{M}$ actein for $24 \mathrm{~h}$, and then flow cytometric analysis was used to calculate apoptotic cells. (C) U937 cells were treated with caspase-3 inhibitor for $2 \mathrm{~h}$ to suppress caspase-3 expression, followed by exposure to $40 \mu \mathrm{M}$ actein for another $24 \mathrm{~h}$, and then western blot analysis was performed to calculate cleaved caspase-3 and ROCK1 expression. (D) Caspase-3 was knocked down using specific siRNA sequence for $24 \mathrm{~h}$, followed by exposure to $40 \mu \mathrm{M}$ actein for another $24 \mathrm{~h}$. Then, all cells were harvested for western blot analysis. Data are analyzed as mean \pm SEM, $\mathrm{n}=8$. ${ }^{* * *} \mathrm{P}<0.001$ versus the actein group.

findings were observed in primary human leukemia cells but not found in peripheral blood mononuclear cells from normal human (Fig. 5C and D). Thus, we supposed that PTEN phosphorylation and $\mathrm{AKT}$ dephosphorylation were related to actein-induced apoptosis in leukemia cells. Following this, RhoA/ROCK1 signaling pathway was investigated in our study. ROCK1 is suggested to be an important target for RhoA, which modulates PTEN activation and regulates apoptotic response. As shown in Fig. 5A and B, actein induced RhoA and ROCK1 downregulation dose- and time-dependently. In agreement with the results above, in primary human leukemia cells, marked reduction of RhoA and ROCK1 were discovered in actein-treated groups, while no significant difference was observed in peripheral blood mononuclear cells extracted from normal people (Fig. 5C and D). In conclusion, the results above indicated that RhoA/ROCK1 was also involved in actein-modulated apoptosis.

Actein-induced apoptosis has a close relationship with RhoA/ROCK1 signaling pathway. Caspase-3 is a key during apoptosis induction, having a close relationship with ROCK1 expression (27). Thus, in this regard, we attempted to explore the role of caspase- 3 in actein-induced apoptosis, and its association with ROCK1. Fig. 6A and C indicated that U937 cells treated with caspase-3 inhibitor, ZVAD, dramatically reduced apoptosis and diminished caspase-3 activation. Also, caspase-3 knockdown with specific siRNA significantly eliminated apoptosis and the cleavage of caspase-3 (Fig. 6B and D). Of note, we found that both suppression of caspase-3 and knockdown of caspase-3 showed no effects on ROCK1 expression via western blot analysis (Fig. 6C and D). Together, the data above indicated that caspase-3 was not in our study included in the regulation of ROCK1 expression during the actein-triggered apoptosis. Thus, the expression of ROCK1 regulated by RhoA possibly was explored using RhoA inhibitor. U937 cells with RhoA inhibitor treatment enhanced apoptosis and cleaved caspase-3, caspase- 9 and PARP expression, especially in actein-cotreatment group. In contrast, ROCK 1 was markedly reduced, indicating that ROCK1 suppressed by actein was dependent on RhoA 

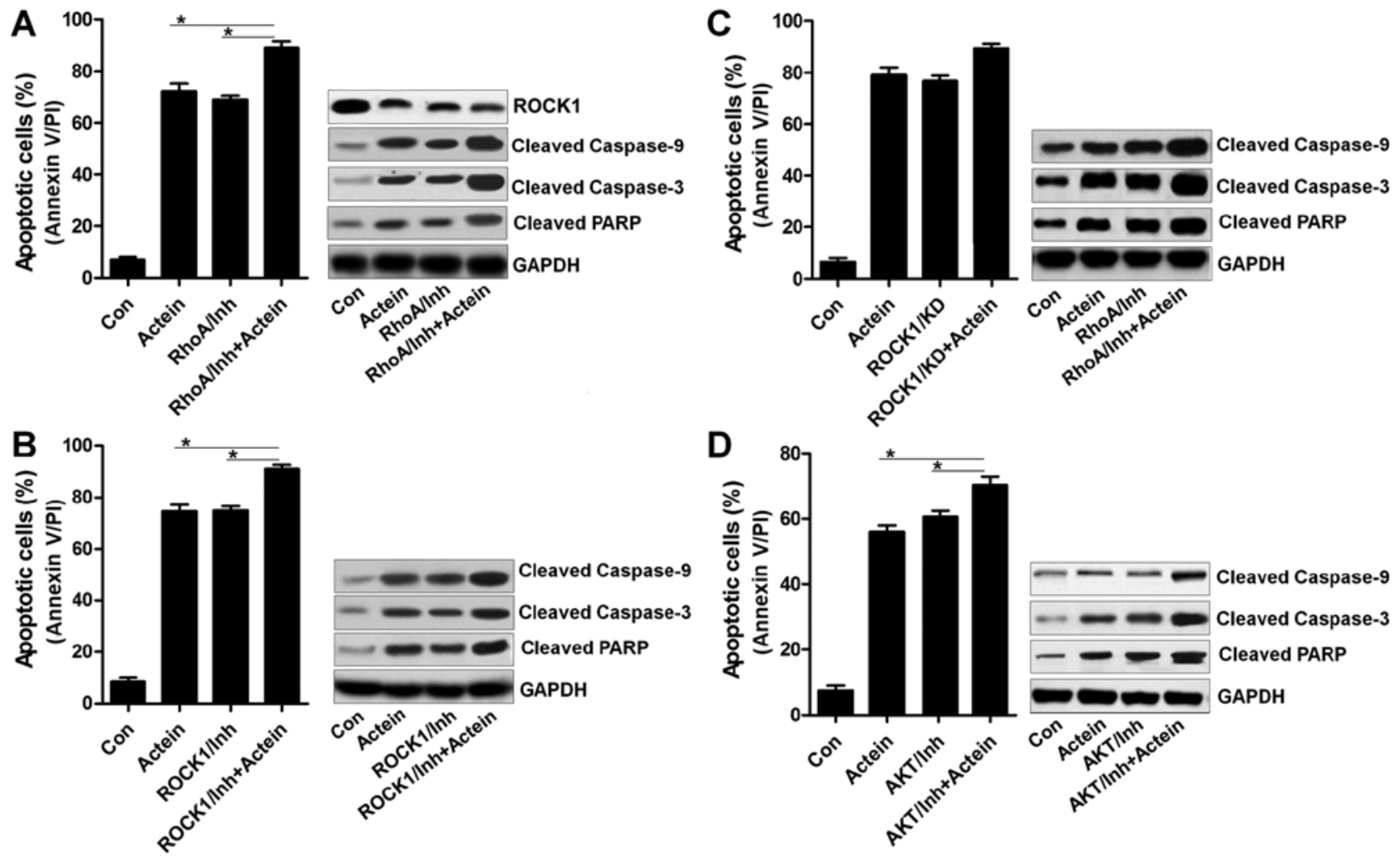

Figure 7. Actein-induced apoptosis has a close relationship with RhoA/ROCK1 signaling pathway. (A) U937 cells were pre-treated with RhoA inhibitor, C3 exoenzyme $(10 \mu \mathrm{M})$, for $2 \mathrm{~h}$, followed by $24-\mathrm{h}$ treatment of actein $(40 \mu \mathrm{M})$. Then, flow cytometry and western blot assays were used to evaluate the apoptosis levels. (B) The inhibitor of ROCK1, Y-27632 dihydrochloride $(10 \mu \mathrm{M})$, was used in U937 cells for suppressing ROCK1 expression, and actein was used to treat cells for another $24 \mathrm{~h}$. Apoptosis was calculated using flow cytometry and western blot analysis. (C) ROCK1 was knocked down using specific siRNA for $24 \mathrm{~h}$, which was then exposed to actein for another $24 \mathrm{~h}$. After various treatments, all cells were harvested for apoptosis analysis using flow cytometry and western blot assays. (D) The inhibitor of AKT, LY294002 $(5 \mu \mathrm{M})$, was used to treat U937 cells for $2 \mathrm{~h}$, and then cells were exposed to actein for another $24 \mathrm{~h}$, followed by flow cytometry and western blot analysis. Data are analyzed as mean $\pm \mathrm{SEM}, \mathrm{n}=8{ }^{* * * *} \mathrm{P}<0.001$ versus the actein group.

expression (Fig. 7A). Then, ROCK1 expression was suppressed using its specific inhibitor and siRNA with the specific sequence. As shown in Fig. 7B and C, we found that suppression of ROCK1 apparently augmented apoptotic response, as well as accelerated caspase-9, caspase-3 and PARP cleavage, which was further upregulated by co-culture with actein. AKT phosphorylated levels could be diminished by using actein. Therefore, its inhibitor was further used here to calculate its effects in apoptosis induced by actein. Fig. 7D suggested that AKT suppression using its inhibitor significantly elevated apoptosis in U937 cells, and its combination with actein further improved apoptotic response, accompanied with upregulated caspase-9, caspase-3 and PARP cleavage. The results above suggested that ROCK1 expression was dependent on RhoA to modulate apoptosis induced by actein in human leukemia cells.

Actein suppresses U937-tumor growth and triggers apoptosis in xenograft mouse models. In vitro, actein was evidenced to be important in suppression of human leukemia cells. In order to further confirm our data above, in vivo experiments were conducted. The male nu/nu mice were subcutaneously injected with U937 cells. After inoculation, half of the total number of mice was administered with actein intraperitoneally for two months. As shown in Fig. 8A, we found that actein administration apparently prolonged the survival rate of mice bearing U937 tumors, which was comparable to the control group. The tumor volume of mice was also dramatically reduced by actein treatment (Fig. 8B). However, no significant difference of body weight was observed between the two groups (Fig. 8C). Next, TUNEL assay and Ki-67 levels were performed to further reveal the role of actein in vivo. Ki-67positive areas were reduced by actein treatment. In contrast, the number of TUNEL-positive cells was upregulated by using actein, indicating apoptosis induced by actein in vivo (Fig. 8D). Furthermore, actein reduced ROCK1 expression in the tumor sections, while caspase- 3 cleavage was found to be enhanced (Fig. 8E). Finally, western blot analysis indicated that RhoA and phosphorylated AKT had low expression in actein-treated group, and caspase-3 cleavage was elevated after actein administration, which were indicative of apoptotic response (Fig. 8F). Thus, the results indicated that actein apparently suppressed U937 tumor growth through triggering apoptosis in vivo.

\section{Discussion}

According to previous studies, RhoA/ROCK1 signaling pathway plays an essential role in cell survival, which has been investigated in various functional states $(18,28,29)$. For instance, several reports indicate evidence that inhibition of the Rho/ROCK signaling pathway induces hepatocellular cancer (HCC) cell apoptosis and endothelial cells via a mito- 

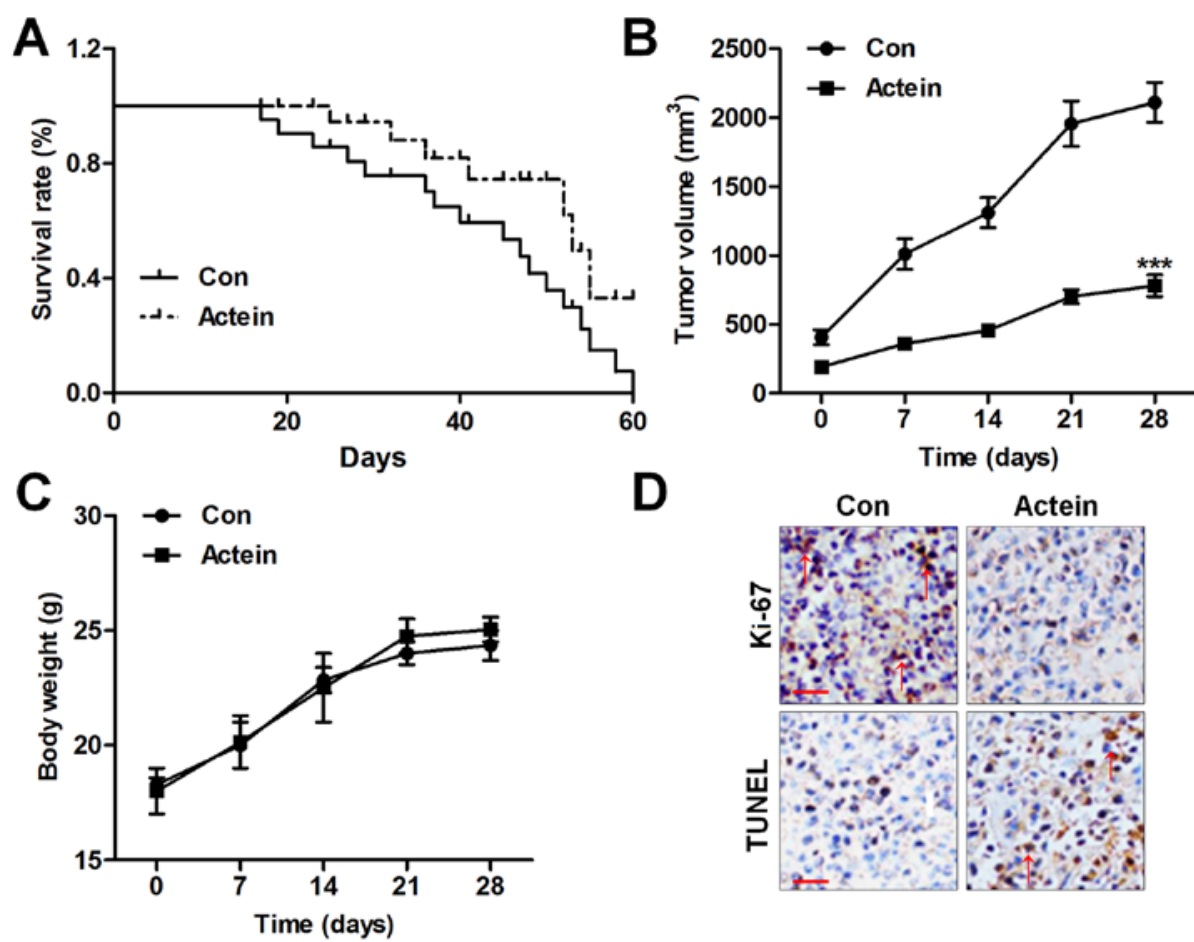

D
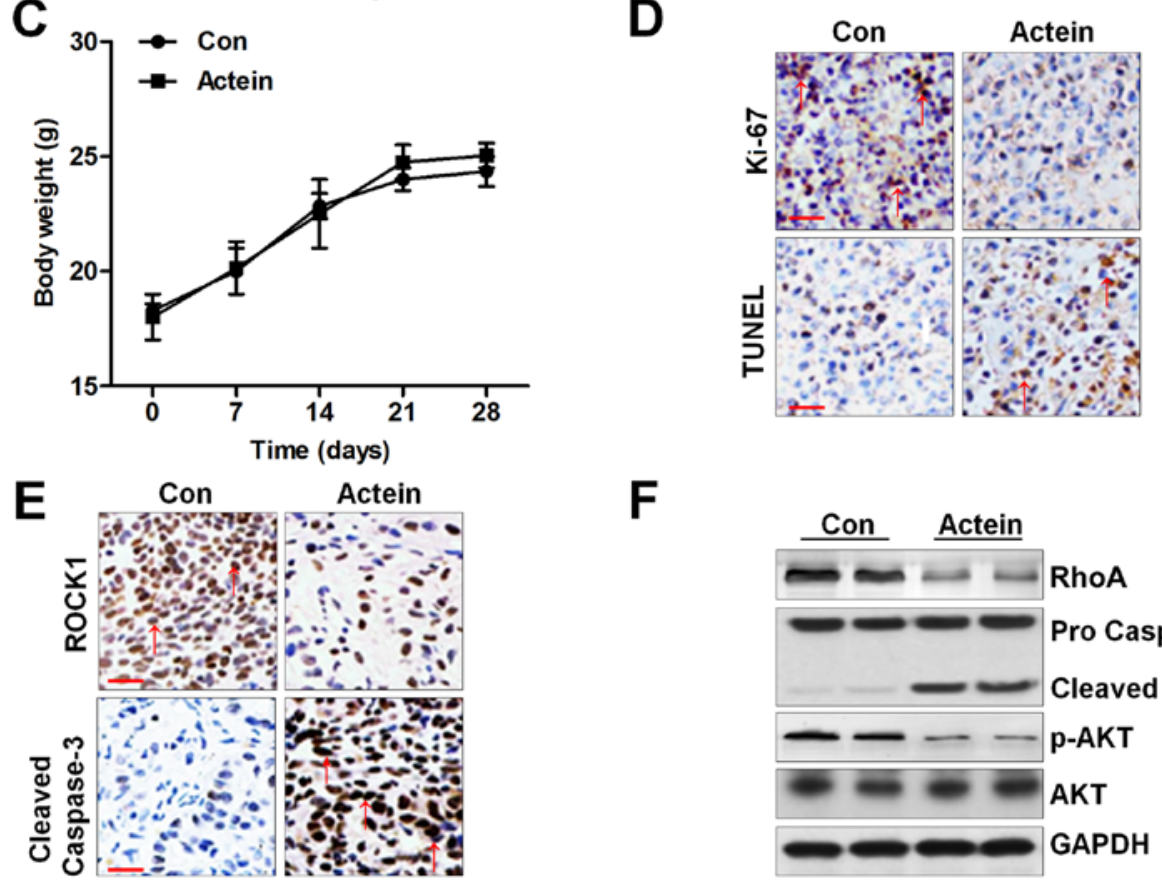

F

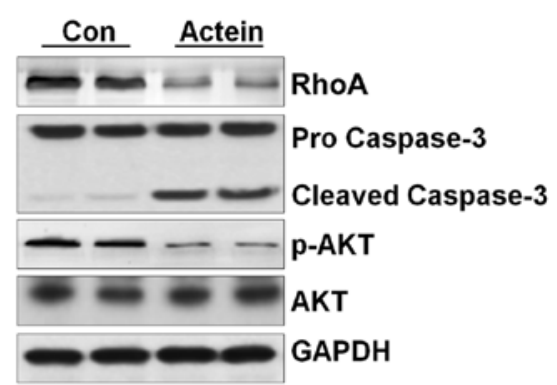

Figure 8. Actein suppresses U937-tumor growth and triggers apoptosis in xenograft mouse models. (A) The survival rate was assessed in xenograft mouse models treated with or without actein. (B) The tumor volume was measured. (C) The body weight was assessed. (D) The immunochemical analysis of Ki-67 and TUNEL is exhibited. (E) ROCK1 and caspase-3 expression levels in tumor tissue sections were analyzed using immunohistochemical assays. (F) Western blot analysis of RhoA, caspase- 3 and AKT in the tumor samples isolated from mice treated under various conditions. Data are analyzed as mean \pm SEM, $\mathrm{n}=10$.

${ }^{* * *} \mathrm{P}<0.001$ versus the Con group.

chondrial apoptosis pathway (30,31). Thus, suppression of RhoA/ROCK1 signaling pathway affects the transformation and proliferation of progenitor cells (32). In addition, as previously reported, RhoA/ROCK1 signaling pathway suppression in human primary leukemia cells enhances cell death, revealing that targeting RhoA/ROCK1 might be of potential value as therapy to prevent human leukemia. In our study, we found that, in line with previous studies, RhoA/ROCK1 pathway was involved in apoptosis of acute promyelocytic leukemia. Apoptosis is an evolutionarily conserved process, which irreversibly eliminates injured or potentially harmful cells in order to protect the organism. The caspases could be structurally divided according to the absence or presence of an N-terminal pro-domain (33). The caspases containing long pro-domains are the first to be activated responding to various apoptotic stimuli (34). The activated caspases damage the cellular architecture and eventually lead to cell death. Caspase- 3 is reported as the most essential member of caspase family $(35,36)$. According to studies before, caspase-3 activation has an association with ROCK1 expression (37). Caspase-3 suppression reduced ROCK1 expression (38). However, there was also a study, which indicated that caspase-3-independent regulation of ROCK1 was observed during apoptosis induction (39). In the present study, U937 cells were exposed to caspase-3 inhibitor of ZVAD and actein diminished caspase-3 cleavage, and apoptosis, while ROCK1 showed no difference, which illustrated that ROCK1 expression was caspase-3-independent, at least in our study, and that other factors might be involved in regulating ROCK1 expression. Attributing to the role of RhoA in modulating ROCK1, it was investigated in our study. Actein exposure induced RhoA downregulation. Also, pre-treatment with RhoA inhibitor in U937 cells, obviously eliminated apoptosis and caspases cleavage triggered by actein. Thus, from the data of our study, RhoA, but not caspase-3, stimulated the expression of ROCK1 in actein-triggered apptosis.

In this study, we found that actein-induced apoptosis in human leukemia cells was observed, which was associated with PTEN and AKT activation. PTEN and AKT phosphorylation play an important role in modulating apoptosis responding to actein treatment. Accumulating evidence elucidated that PTEN, a ROCK1 substrate, is suggested to be a negative modulator of PI3K/AKT signaling pathway (40). 
Consistent with previous studies, PTEN negatively regulated AKT activation during actein-induced apoptosis in our study. AKT phosphorylation was decreased by actein treatment, and its suppression using specific inhibitor abrogated apoptosis and caspase activation.

Bcl-2 family proteins, including anti-apoptotic members (Bcl-2, Mcl-1, and Bcl-xl) and pro-apoptotic members (Bax), play a crucial role in apoptosis $(41,42)$. Bcl-2 has been known to form a heterodimeric complex with the pro-apoptotic member Bax, neutralizing its pro-apoptotic effects. Thus, the $\mathrm{Bcl}-2 / \mathrm{Bax}$ ratio is a decisive factor and plays a significant role in determining if cells are likely to undergo survival or death (43). Similarly, in our study, Bcl-2, Bcl-xl and Mcl-1 were highly reduced by using actein, indicating apoptosis induction and contributing to cell death. Also, the high expression of Bax in mitochondria contributes to apoptosis formation through releasing Cyto- $c$ into cytoplasm (44). Also, we found that Bax was expressed highly in actein-treated U937 cells. In addition, accordingly, the release of Cyto- $c$ into the cytoplasm was observed, which was in line with a previous study (45).

In conclusion, this study indicated that actein selectively triggered apoptotic response and mitochondrial damage in human leukemia cell lines, as well as in human primary leukemia cells, and showed no effects on peripheral blood mononuclear cells isolated from normal healthy humans. Furthermore in vivo, actein suppressed the growth of U937 tumor through activating PTEN/caspases and inactivating RhoA/ROCK1/AKT signaling pathways. Thus, we supposed that actein could be applied as a safe and effective candidate to treat human leukemia through inducing apoptosis.

\section{References}

1. Shivarov V and Bullinger L: Expression profiling of leukemia patients: Key lessons and future directions. Exp Hematol 42: 651-660, 2014.

2. Ross K, Gillespie-Twardy AL, Agha M, Raptis A, Hou JZ, Farah R, Redner RL, Im A, Duggal S, Ding F, et al: Intensive chemotherapy in patients aged 70 years or older newly diagnosed with acute myeloid leukemia. Oncol Res 22: 85-92, 2015.

3. Wang ES: Treating acute myeloid leukemia in older adults. Hematology (Am Soc Hematol Educ Program) 2014: 14-20, 2014

4. Mayer J, Arthur C, Delaunay J, Mazur G, Thomas XG, Wierzbowska A, Ravandi F, Berrak E, Jones M, Li Y, et al: Multivariate and subgroup analyses of a randomized, multinational, phase 3 trial of decitabine vs treatment choice of supportive care or cytarabine in older patients with newly diagnosed acute myeloid leukemia and poor- or intermediate-risk cytogenetics. BMC Cancer 14: 69, 2014.

5. Kantarjian HM, Thomas XG, Dmoszynska A, Wierzbowska A, Mazur G, Mayer J, Gau JP, Chou WC, Buckstein R, Cermak J, et al: Multicenter, randomized, open-label, phase III trial of decitabine versus patient choice, with physician advice, of either supportive care or low-dose cytarabine for the treatment of older patients with newly diagnosed acute myeloid leukemia. J Clin Oncol 30: 2670-2677, 2012.

6. Dombret H, Seymour JF, Butrym A, Wierzbowska A, Selleslag D, Jang JH, Kumar R, Cavenagh J, Schuh AC, Candoni A, et al: International phase 3 study of azacitidine vs conventional care regimens in older patients with newly diagnosed AML with $>30 \%$ blasts. Blood 126: 291-299, 2015.

7. Zhou T, Hasty P, Walter CA, Bishop AJ, Scott LM and Rebel VI: Myelodysplastic syndrome: An inability to appropriately respond to damaged DNA? Exp Hematol 41: 665-674, 2013.

8. Einbond LS, Shimizu M, Nuntanakorn P, Seter C, Cheng R, Jiang B, Kronenberg F, Kennelly EJ and Weinstein IB: Actein and a fraction of black cohosh potentiate antiproliferative effects of chemotherapy agents on human breast cancer cells. Planta Med 72: 1200-1206, 2006.
9. Einbond LS, Mighty J, Redenti S and Wu HA: Actein induces calcium release in human breast cancer cells. Fitoterapia 91: 28-38, 2013.

10. Yue GGL, Xie S, Lee JKM, Kwok HF, Gao S, Nian Y, Wu XX, Wong CK, Qiu MH and Lau CB: New potential beneficial effects of actein, a triterpene glycoside isolated from Cimicifuga species, in breast cancer treatment. Sci Rep 6: 35263, 2016.

11. Yang ZC and Ma J: Actein enhances TRAIL effects on suppressing gastric cancer progression by activating p53/caspase-3 signaling. Biochem Biophys Res Commun: Nov 30, 2016 (Epub ahead of print). doi: 10.1016/j.bbrc.2016.11.162.

12. Einbond LS, Shimizu M, Ma H, Wu HA, Goldsberry S, Sicular S, Panjikaran M, Genovese G and Cruz E: Actein inhibits the $\mathrm{Na}^{+}-\mathrm{K}^{+}$-ATPase and enhances the growth inhibitory effect of digitoxin on human breast cancer cells. Biochem Biophys Res Commun 375: 608-613, 2008.

13. Harris SL and Levine AJ: The p53 pathway: Positive and negative feedback loops. Oncogene 24: 2899-2908, 2005.

14. Lin MW, Wu CT, Shih JY, Chang YL and Yang PC: Clinicopathologic characteristics and prognostic significance of EGFR and p53 mutations in surgically resected lung adenocarcinomas $\leq 2 \mathrm{~cm}$ in maximal dimension. J Surg Oncol 110: 99-106, 2014.

15. Xu Y, Wang L, Zheng X, Liu G, Wang Y, Lai X and Li J: Positive expression of p53, c-erbB2 and MRP proteins is correlated with survival rates of NSCLC patients. Mol Clin Oncol 1: 487-492, 2013.

16. Lee JH, Katakai T, Hara T, Gonda H, Sugai M and Shimizu A: Roles of p-ERM and Rho-ROCK signaling in lymphocyte polarity and uropod formation. J Cell Biol 167: 327-337, 2004.

17. Osiak AE, Zenner G and Linder S: Subconfluent endothelial cells form podosomes downstream of cytokine and RhoGTPase signaling. Exp Cell Res 307: 342-353, 2005.

18. Benitah SA, Valerón PF and Lacal JC: ROCK and nuclear factor-kappaB-dependent activation of cyclooxygenase- 2 by Rho GTPases: Effects on tumor growth and therapeutic consequences. Mol Biol Cell 14: 3041-3054, 2003.

19. Cai L, Threadgill MD, Wang Y and Li M: Effect of poly (ADP-ribose) polymerase-1 inhibition on the proliferation of murine colon carcinoma CT26 cells. Pathol Oncol Res 15: 323-328, 2009.

20. Ratnam K and Low JA: Current development of clinical inhibitors of poly(ADP-ribose) polymerase in oncology. Clin Cancer Res 13: 1383-1388, 2007.

21. Takeba Y, Matsumoto N, Watanabe M, Takenoshita-Nakaya S, Ohta Y, Kumai T, Takagi M, Koizumi S, Asakura T and Otsubo T: The Rho kinase inhibitor fasudil is involved in p53-mediated apoptosis in human hepatocellular carcinoma cells. Cancer Chemother Pharmacol 69: 1545-1555, 2012.

22. Tortora G, Caputo R, Damiano V, Caputo R, Troiani T, Veneziani BM, De Placido S, Bianco AR, Zangemeister-Wittke U and Ciardiello F: Combined targeted inhibition of bcl-2, bcl-XL, epidermal growth factor receptor, and protein kinase A type I causes potent antitumor, apoptotic, and antiangiogenic activity. Clin Cancer Res 9: 866-871, 2003.

23. Riedl SJ and Shi Y: Molecular mechanisms of caspase regulation during apoptosis. Nat Rev Mol Cell Biol 5: 897-907, 2004.

24. Yang JY, Della-Fera MA, Rayalam S and Baile CA: Enhanced effects of xanthohumol plus honokiol on apoptosis in 3T3-L1 adipocytes. Obesity (Silver Spring) 16: 1232-1238, 2008.

25. Roy S, Yu Y, Padhye SB, Sarkar FH and Majumdar AP: Difluorinated-curcumin (CDF) restores PTEN expression in colon cancer cells by down-regulating miR-21. PLoS One 8: e68543, 2013

26. Mueller S, Phillips J, Onar-Thomas A, Romero E, Zheng S, Wiencke JK, McBride SM, Cowdrey C, Prados MD, Weiss WA, et al: PTEN promoter methylation and activation of the PI3K/ Akt/mTOR pathway in pediatric gliomas and influence on clinical outcome. Neuro-oncol 14: 1146-1152, 2012.

27. Liu Y, Minze LJ, Mumma L, Li XC, Ghobrial RM and Kloc M: Mouse macrophage polarity and ROCK1 activity depend on RhoA and non-apoptotic caspase 3. Exp Cell Res 341: 225-236, 2016.

28. Gilkes DM, Xiang L, Lee SJ, Chaturvedi P, Hubbi ME, Wirtz D and Semenza GL: Hypoxia-inducible factors mediate coordinated RhoA-ROCK1 expression and signaling in breast cancer cells. Proc Natl Acad Sci USA 111: E384-E393, 2014.

29. Wang Y, Wang D and Guo D: miR-124 promote neurogenic transdifferentiation of adipose derived mesenchymal stromal cells partly through RhoA/ROCK 1 , but not ROCK 2 signaling pathway. PLoS One 11: e0146646, 2016. 
30. Zhang JG, Li XY, Wang YZ, Zhang QD, Gu SY, Wu X, Zhu GH, $\mathrm{Li} \mathrm{Q}$ and Liu GL: ROCK is involved in vasculogenic mimicry formation in hepatocellular carcinoma cell line. PLoS One 9: e107661, 2014

31. Peng H, Luo P, Li Y, Wang C, Liu X, Ye Z, Li C and Lou T: Simvastatin alleviates hyperpermeability of glomerular endothelial cells in early-stage diabetic nephropathy by inhibition of RhoA/ROCK1. PLoS One 8: e80009, 2013.

32. Lin SC, Gou GH, Hsia CW, Ho CW, Huang KL, Wu YF, Lee SY and Chen YH: Simulated microgravity disrupts cytoskeleton organization and increases apoptosis of rat neural crest stem cells via upregulating CXCR4 expression and RhoA-ROCK1-p38 MAPK-p53 signaling. Stem Cells Dev 25: 1172-1193, 2016

33. Altieri DC: Survivin and IAP proteins in cell-death mechanisms. Biochem J 430: 199-205, 2010

34. Mohan S, Abdul AB, Abdelwahab SI, Al-Zubairi AS, Sukari MA, Abdullah R, Elhassan Taha MM, Ibrahim MY and Syam S: Typhonium flagelliforme induces apoptosis in CEMss cells via activation of caspase-9, PARP cleavage and cytochrome $c$ release: Its activation coupled with G0/G1 phase cell cycle arrest. J Ethnopharmacol 131: 592-600, 2010.

35. Liu X, Zou H, Slaughter C and Wang X: DFF, a heterodimeric protein that functions downstream of caspase-3 to trigger DNA fragmentation during apoptosis. Cell 89: 175-184, 1997.

36. Grütter MG: caspases: Key players in programmed cell death Curr Opin Struct Biol 10: 649-655, 2000.

37. Wang Y, Xu J and Gu Y: 37 1, $25(\mathrm{OH}) 37$ 1,25(OH)2D3 suppresses oxidative stress-induced microparticle release by placental trophoblasts: Placenta and decidua. Pregnancy Hyperens 6: 154, 2016.
38. Shen K, Wang Y, Zhang Y, Zhou H, Song Y, Cao Z, Kou J and Yu B: Cocktail of four active components derived from Sheng Mai San inhibits hydrogen peroxide-induced PC12 cell apoptosis linked with the caspase-3/ROCK1/MLC pathway. Rejuvenation Res 18: 517-527, 2015.

39. Li G, Zhou T, Liu L, Chen J, Zhao Z, Peng Y, Li P and Gao N: Ezrin dephosphorylation/downregulation contributes to ursolic acid-mediated cell death in human leukemia cells. Blood Cancer J 3: e108, 2013.

40. Peng H, Cao J, Yu R, Danesh F, Wang Y, Mitch WE, Xu J and $\mathrm{Hu} \mathrm{Z}$ : CKD stimulates muscle protein loss via rho-associated protein kinase 1 activation. J Am Soc Nephrol 27: 509-519, 2016.

41. Heath-Engel HM, Chang NC and Shore GC: The endoplasmic reticulum in apoptosis and autophagy: Role of the BCL-2 protein family. Oncogene 27: 6419-6433, 2008.

42. Martinou JC and Youle RJ: Mitochondria in apoptosis: Bcl-2 family members and mitochondrial dynamics. Dev Cell 21: 92-101, 2011.

43. Levine B, Sinha S and Kroemer G: Bcl-2 family members: Dual regulators of apoptosis and autophagy. Autophagy 4: 600-606, 2008.

44. Arnoult D, Parone P, Martinou JC, Antonsson B, Estaquier J and Ameisen JC: Mitochondrial release of apoptosis-inducing factor occurs downstream of cytochrome $c$ release in response to several proapoptotic stimuli. J Cell Biol 159: 923-929, 2002.

45. Sheridan C, Delivani P, Cullen SP and Martin SJ: Bax- or Bak-induced mitochondrial fission can be uncoupled from cytochrome $c$ release. Mol Cell 31: 570-585, 2008. 